\title{
Assessing soil-structure interaction during the 2016 central Italy seis- mic sequence (Italy): preliminary results
}

\author{
ARRIGO CASERTA*, FAWZI DOUMAZ*, ANTONIO COSTANZO**, \\ ANNA GERVASI ${ }^{* *}$, WILLIAM THOROSSIAN ${ }^{*}$, SERGIO FALCONE**, \\ CARMELO LA PIANA**, MARIO MINASI ${ }^{* *}$, MARIA FABRIZIA \\ BUONGIORNO* \\ *Istituto Nazionale di Geofisica e Vulcanologia, INGV, Se- \\ zione CNT-Roma, Via di Vigna Murata 605, 00143 Roma, I- \\ taly \\ ** Istituto Nazionale di Geofisica e Vulcanologia, INGV, Se- \\ zione CNT-Rende, Via P. Bucci cubo 30C, 87036 Rende (CS), \\ Italy \\ arrigo.caserta@ingv.it
}

\begin{abstract}
We used the moderate-magnitude aftershocks succeeding to the 2016 August 24th, Mw $=6.0$, Amatrice (Italy) mainshock to asses, especially during an ongoing seismic sequence, the soil-structure interaction where cultural Heritage is involved. We have chosen as case study the San Giovanni Battista church (A.D. 1039) in Acquasanta Terme town, about $20 \mathrm{Km}$ northeast of Amatrice. First of all we studied the soil shaking features in order to characterize the input to the monument. Then, using the recordings in the church, we tried to figure out how the input seismic energy is distributed over the different monument parts. Some preliminary results are shown and discussed.
\end{abstract}

\section{INTRODUCTION}

$\mathrm{D}$ uring the moderate magnitude aftershocks following the Amatrice earthquake (Mw=6.0) occurred on August 24, 2016 we installed eight portable seismic stations in the Acquasanta Terme town, located at about $20 \mathrm{~km}$ northeast of the mainshock zone (cf. Fig. 1a).
The aim is to study the interaction between the incoming seismic wave-field and the San Giovanni Battista Church (A.D. 1039), a relevant cultural heritage in the town. Such seismic sequence, indeed, offers a singular opportunity to calibrate the monument response to Central Apennines earthquakes, which have been responsible for the largest damage to the cultural 
heritage disseminated in the whole Central Italy(e.g. [Parisi and Augenti, 2013]).

In a first step, we installed an array of five seismic stations in the town (red triangles in Fig. 1b). Then, to study the dynamic behavior of the monumental structure under the action of the incoming wave-field, we installed three seismic stations inside the church (green triangles in Fig 1b). The locations of these stations were chosen in order to study mainly the interaction between the bell tower and the rest of the church structure.

In the same time, in order to estimate the state of the health of the monument, we coupled a terrestrial laser scanner (TLS) campaign with some in-door and out-door drone photogrammetric flights. Thermographic survey of the walls was done to reveal earthquake induced structural inconsistencies on the monument. In particular, the TLS high resolution scans allow to perform a detailed geometrical analysis of the structure (e.g. verticality of walls, shifts), whereas the shootings with drone allow to cover the non-visible parts from the ground and the unreachable nor inaccessible ones. The geometrical analysis is combined with thermographic inspection of the external walls following the procedure proposed by [Costanzo et al., 2015]. The repetition of the surveys during and after the seismic sequence allow an evaluation of the changes produced (cf. [Teza et al., 2015]).

\section{GEOLOGICAL SETTING}

The town centre of Acquasanta Terme is located on the eastern side of the Tronto River, moreover the whole municipality is made up of many hamlets settled on both sides of the Tronto Valley. The town is built on terraces constituted by variable thickness of alluvial deposits resting on a travertine layer. This later is on top of the bedrock represented by calcar- eous-marly formation, named marl with Cerrogna and Bisciaro (see geological map in Fig. $1 \mathrm{~b}$ and schematic section in Fig. 2).

It is known that such stratigraphy is prone to amplify soil shaking. Our purpose is to quantify such effects, identifying also at what frequencies the amplification takes place.
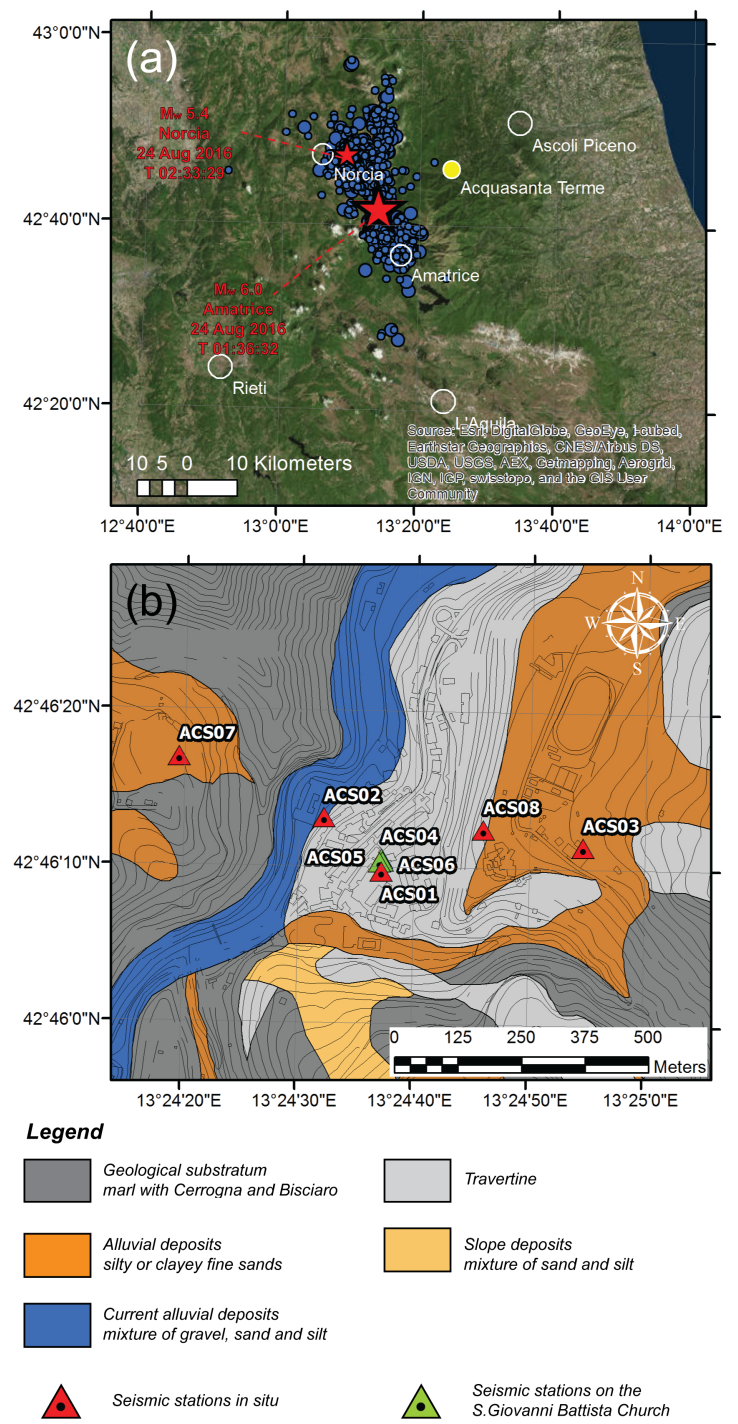

Figure 1: (a) Epicenters (small circles) of the August 2016 Amatrice seismic sequence. The bigger red star represents the mainshock. (b) Geological map of the near-surface geology of Acquasanta Terme town, the red and green triangles represent the installed seismic stations for this study. 


\section{THE EXPERIMENTS}

Temporary seismic stations were deployed along a WNW-ESE profile, where the geological section crosses the Tronto Valley intersecting: (i) the San Vito village (station ACS07 at WNW), (ii) the bottom of valley at the contact between travertine and Bisciaro (station ACS02), (iii) the centre of Acquasanta (station ACS01), (iv) the transition between the outcropping travertine and alluvial deposits (station ACS08) and (v) the Cagnano village (station ACS03 at ESE), (see Figure 1).

The array was designed to investigate the role played by near-surface geology in amplifying the soil shaking and to check the presence of any topographic effects.

Only three seismic stations were available to study the dynamic response of the main historical building of the town, i.e., S. Giovanni Battista church, to the seismic radiation. We focused our attention only on the dynamic of interaction between the bell tower structure and the church built. For this purpose, we installed one station at the top of bell tower and the other two on the lateral walls of the church on top of two facing pillars (see Figure 3).

Another station ACS01 was installed in the church garden: the transducers were buried 20 $\mathrm{cm}$ below the ground level at distance of about $13 \mathrm{~m}$ from the building. The latter station was used as reference station.

Each seismic stations is composed by CENTAUR seismic digitizer [Nanometrics, 2016a] equipped with triaxial a TRILLIUM broadband seismometer [Nanometrics, 2016b] and a triaxial TITAN accelerometric transducer [Nanometrics, 2016c]. The horizontal components were oriented along the north-south and east-west directions. Data were sampled at 250
$\mathrm{Hz}$ using 24-bit analog-to-digital converters, and time synchronism was provided by the embedded GPS system at each station.

Furthermore, all stations were equipped with solar panels for power supply and battery charging. A local Wireless (WiFi) network were installed for data transmission thanks also to a set of antennas connected to each station and to a server hosted in the municipal seat of the town. Such data transmission was based on HyperLAN $5 \mathrm{GHz}$ band. This latter is a wireless access broadband technology based on standards suggested by ETSI (European Telecommunications Standard Institute), more efficient than the usual WI-FI transmission and networking, specially, on a wide and morphologically problematic coverage area allowing us to better design the station network. All data collected by seismic stations were real-time transmitted to the server.

\section{RESULTS}

The preliminary results shown in this paper are referred to one of the aftershocks $(\mathrm{Mw}=3.4)$ occurred on the 30 September 2016, localized at about $20 \mathrm{Km}$ in NW-SE direction respect to the Acquasanta Terme town.

In order to identify the soil shaking amplification frequencies and to quantify their amplitudes, we adopted the technique based on Standard Spectral Ratio (SSR, [Borcherdt, 1970]), defined as the ratio of the Fourier amplitude spectra of a site and that one at the reference site obtained from the same earthquake and the same component.

Our reference station is ACS02 (Figure 2) located at the contact between the travertine layer and the bedrock. The N-S and E-W component were rotated into radial (R) and transverse $(\mathrm{T})$ directions, using the station-toepicenter azimuth. A window length was set 
equal to the whole earthquake duration. The Fourier spectra were smoothed with a Konno and Omachi (1998) algorithm, implemented in the Geopsy freeware software suite (http://www.geopsy.org/), hence, the spectral ratio was calculated for the three
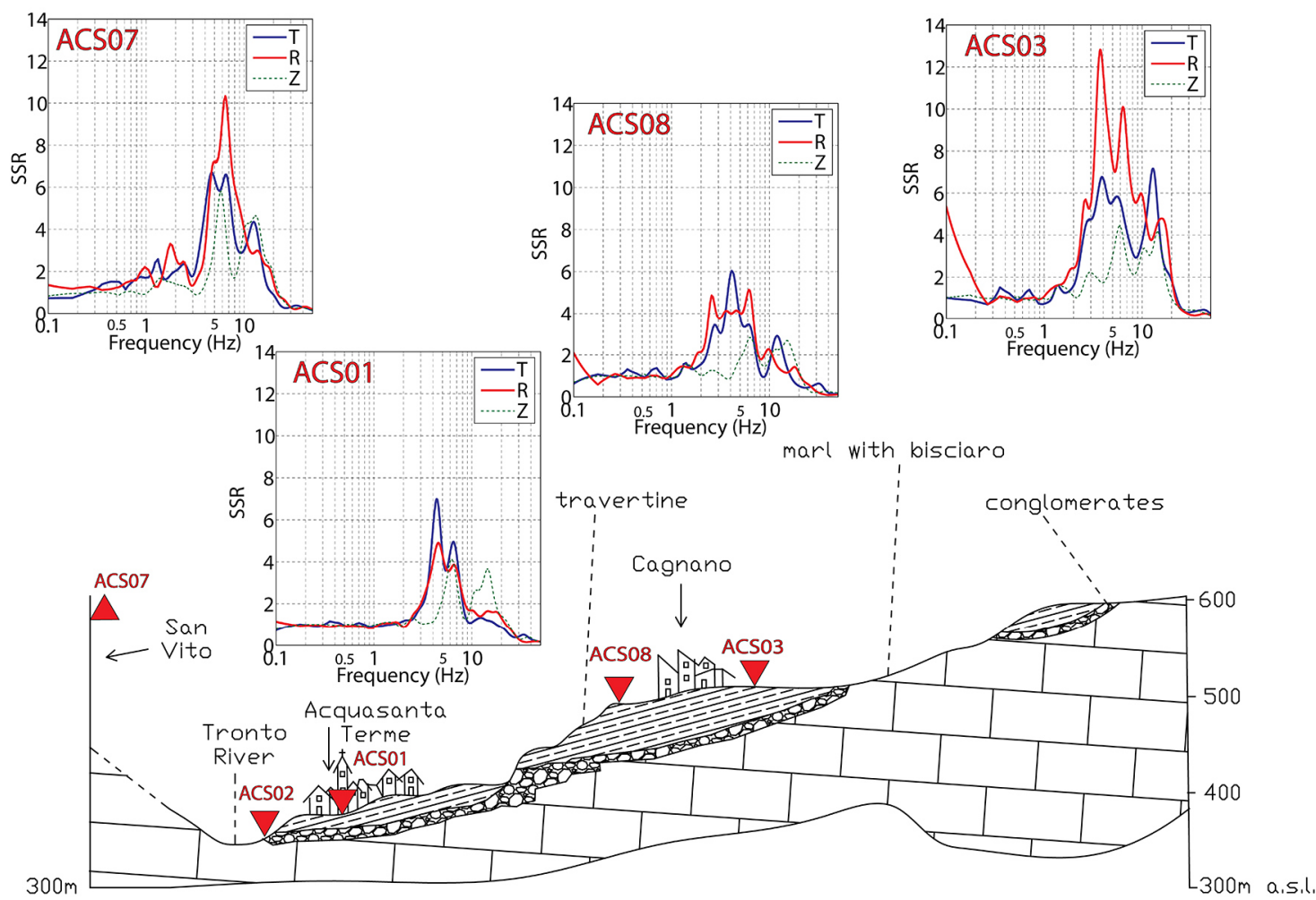

Figure 2. Projection of the linear array in Figure 1 along 2D profile showing the near-surface geology (modified by [Boni and Colacicchi, 1966]). The standard spectral ratio is shown for each seismic station.

components (Figure 2) through a script developed by authors in MATLAB $^{\circledR}$ [The MathWorks, 2010].

The radial and transverse SSR curves in correspondence of the town center are very similar, showing a relevant amplification in the frequency range between $3 \mathrm{~Hz}$ and $8 \mathrm{~Hz}$ and two recognizable peaks at about $4.5 \mathrm{~Hz}$ and $6.5 \mathrm{~Hz}$ with amplification values higher than 4 for both components. In the San Vito village, moving in direction WNW at an altitude of $85 \mathrm{~m}$ above the reference site (ACS02), the amplification peaks occur at the same frequencies of the previous site (ACS01), however is shown a third peak at $12.5 \mathrm{~Hz}$ on the transverse component and increased values for the first two, in particular the one at $6.5 \mathrm{~Hz}$ where the factor is 10 for the radial component. Instead, in the direction ESE towards the Cagnano hamlet, at the transition limit between the outcropping travertine and the sedimentary cover (ACS08), we find a wider frequency range respect to the previous sites towards the low frequencies (2$8 \mathrm{~Hz}$ ) and a shift of the first peak at $2.5 \mathrm{~Hz}$ for the radial component. Finally, on the Cagnano upper site (ACS03), where the alluvial deposits 
are thick about $30 \mathrm{~m}$, in the range $2-10 \mathrm{~Hz}$ the radial component is more amplified respect to the other sites, as well as to the transverse, showing an amplification factor (SSR) higher than 4 and different peaks with value up to 13 . In these latter sites of Cagnano, as already described for San Vito, appears a third peak on the transverse component at about $12.5 \mathrm{~Hz}$, that increasing with the elevation.

With reference to the site of the church garden (ACS01), the SSR amplification factor was calculated for the stations installed on the religious building. The NS and EW horizontal components were rotated along the longitudinal and transverse directions of the lateral walls of the church, respectively. In the upper panel of the Figure 3 is shown a picture of the preliminary 3D model, which was reconstructed through data obtained by terrestrial laser scanning and aerial photogrammetric surveys. On the picture the positions of the ACS05 and ACS04 stations are given; instead, the third station, ACS06, is located on the window of wall opposite to that of the ACS04 station. In the lower panel of the figure, the SSR curves are reported for the visible stations.
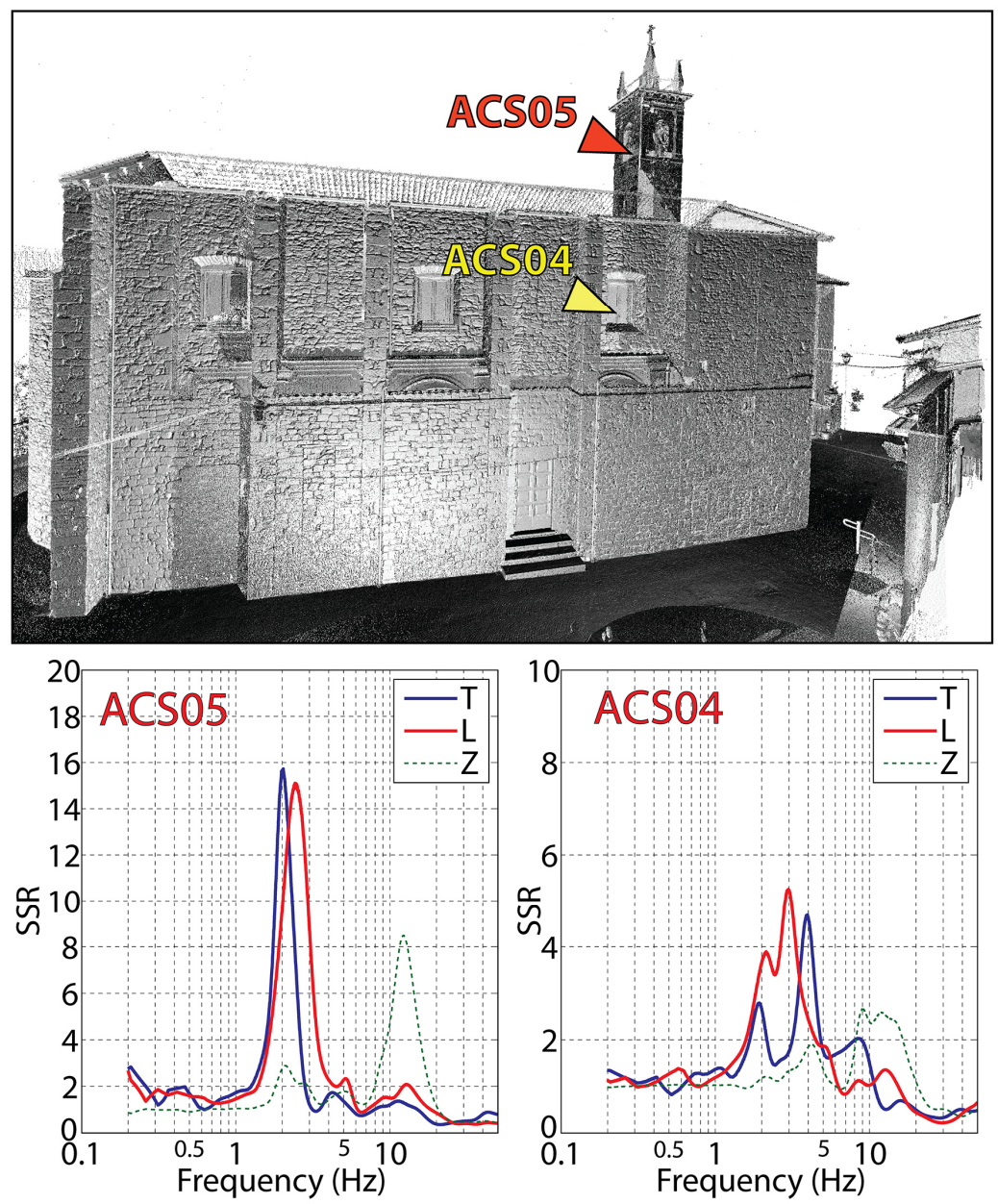

Figure 3. Top panel: geometrical reconstruction of the San Giovanni Battista Church using the terrestrial laser scanner (TLS) data, with locations of the seismic stations. Bottom panel: The standard spectral ratio for each seismic station. 
Analyzing the response of the bell tower, we find two frequencies of amplification well recognizable: one along the transverse direction around $2 \mathrm{~Hz}$ and the other one on the orthogonal at $2.5 \mathrm{~Hz}$. The peak value for the two directions is almost the same, indicating an amplification of 15 times respect to the foundation soil. Instead, the structural response of the church wall shows a peak in correspondence of the same frequencies of the tower with factors of about 4 and 5 lower for longitudinal and transverse component, respectively; therefore, the amplifications at these frequencies are probably due to the normal mode of the tower bell transmitted to the church.

Moreover, the SSR curves relative to the wall assume another predominant peak at $3 \mathrm{~Hz}$ and $4 \mathrm{~Hz}$ for the longitudinal and transverse direction, respectively, which may be linked to local or global normal modes of the church.

\section{DisCUSSION AND FUTURE DEVELOPMENT}

We have designed and installed a seismic array in Acquasanta Terme to investigate soil shaking features and cultural heritage response to the incoming seismic radiation. The preliminary results show the variability of the site amplification along the Tronto Valley both in frequencies and amplitudes, due to the nearsurface geology as well as to topography. With regard to the S. Giovanni Church, the spectral ratios allow to deduce some observations on the structural response. In particular, the transverse resonance frequency of the church wall $(4 \mathrm{~Hz})$ is very close to the free-field frequency $(4.5 \mathrm{~Hz})$. Therefore, using the soilstructure resonance factor proposed by [Gosar, $2010]$, we obtain a value of about $12 \%$, hence, a high danger (factor $\leq 15 \%$ ). Instead, the same factor calculated for the bell tower $(44 \%$ for frequency $2.5 \mathrm{~Hz}$ ) suggests a low danger (factor $>25 \%$ ) for this part of the structure. Such results are in agreement with the preliminary observed monument damages.

The analysis on the whole dataset (not only concerning the seismic records, but also the geometric and thermographic surveys) coupled with a numerical modeling will better explain the structural response. This will be the topic of a forthcoming paper. The data and analysis obtained by this research, as well as providing the induced-earthquake damage, will drive the restoration of the cultural heritage.

\section{ACKNOWLEDGEMENTS}

The authors are grateful to citizens, mayor and public administration of Acquasanta Terme for their support during the deployment of the activities. We also thank the priests of the S. Giovanni Battista Church for their availability and the firefighters, who provided the technical support for the installation of the seismic stations on the bell tower and the church walls. Finally, we thank anonymous reviewer and the editor, who provided valuable suggestions to improve the manuscript. This work was possible thanks to the instrumentation funded by Ministry of Education, University and Research under the research project PON0102710 “MASSIMO".

\section{REFERENCES}

[Boni and Colacicchi, 1966] Boni, C. and Colacicchi, R. (1966). I travertini della Valle del Tronto.Mem. Soc. Geol. It., Vol.5, 315-339.

[Borcherdt, 1970]Borcherdt, R.D. (1970). Effects of local geology on ground motion near San Francisco Bay. Bull. Seism. Soc. Am., Vol. 60, pp. 29-61. 
[Costanzo et al., 2015] Costanzo, A.; Minasi, M.; Casula, G.; Musacchio, M.; Buongiorno, M.F. (2015) Combined Use of Terrestrial Laser Scanning and IR Thermography Applied to a Historical Building. Sensors 2015, 15, 194-213. doi:10.3390/s150100194.

[Gosar, 2010] Gosar, A. (2010). Site effects and soil-structure resonance study in the Kobarid basin (NW Slovenia) using microtremors. Natural Hazards and Earth System Sciences, 10, 761-772.

[Konno and Ohmachi, 1998] Konno, K., and Ohmachi T. (1998). Ground-motion characteristics estimated from spectral ratio between horizontal and vertical components of microtremor, B. Seismol. Soc. Am., 88, 228-241. [Nanometrics, 2016a] Nanometrics, Inc. (2016). CENTAUR technical specifications, Kanata, Ontario, Canada, available on line: www.nanometrics.ca/seismology/products/d igitizers/centaur, (accessed on November 11, 2016).

[Nanometrics, 2016b] Nanometrics, Inc. (2016). TRILLIUM COMPACT technical specifica- tions, Nanometrics, Inc., Kanata, Ontario, Canada, available on line:www.nanometrics.ca/seismology/produc ts/trillium-compact, (accessed on November 11, 2016).

[Nanometrics, 2016c] Nanometrics, Inc. (2016). TRILLIUM COMPACT technical specifications, Kanata, Ontario, Canada, available on line:www.nanometrics.ca/seismology/produc ts/titan, (accessed on November 11, 2016).

[The MathWorks, 2010], The MathWorks, Inc., MATLAB and Statistics Toolbox Release 2010a, Natick, Massachusetts, United States.

[Parisi and Augenti, 2013] Parisi F. and Augenti N. (2013). Earthquake damages to cultural heritage constructions and simplified assessment of artworks, Engineering Failure Analysis, 2013, 34, 735-760, ISSN 1350-6307.

[Teza at al., 2015] Teza, G.; Pesci, A.; Trevisani, S. (2015). Multisensor surveys of tall historical buildings in high seismic hazard areas before and during a seismic sequence, Journal of Cultural Heritage, 2015, 16 (3), 255-266, dx.doi.org/10.1016/j.culher.2014.06.008 